\title{
A robust chemical weathering index applicable to a wide range of sedimentary rocks
}

\author{
T. $\mathrm{CHO}^{1 *}$, T. OHTA ${ }^{2}$
}

${ }^{1}$ Department of Earth Sciences, Resources and Environmental Engineering, Graduate School of Creative Science and Engineering, Waseda University, 1-6-1, Nishiwaseda, Shinjuku, Tokyo 169-8050, Japan (*correspondence: tianct@fuji.waseda.jp)

${ }^{2}$ Department of Earth Sciences, Faculty of Education and Integrated Arts and Sciences, Waseda Univ., 1-6-1, Nishiwaseda, Shinjuku, Tokyo 169-8050, Japan

For the aim of reconstructing paleoweathering conditions, a lot of weathering indices using major elements were developed up until now (e.g. CIA; Nesbitt and Young, 1982, WIP; Parker, 1970, W index; Ohta and Arai, 2007). To calculating these indices, the concentration of silicate-bound $\mathrm{CaO}$ is required because $\mathrm{Ca}$ is one of the most soluble elements in silicate rock during weathering. However, when applying these indices to the whole-rock composition of sedimentary rock, estimating the concentration of silicatebound $\mathrm{CaO}$ is often a crucial problem because of the existence of carbonate or phosphate. In this study, a new weathering index, which does not include $\mathrm{CaO}$, was introduced. The new weathering index was successfully derived from the dataset of major element compositions of fresh igneous rock and their weathering profiles $(n=293)$ by using independent component analysis (ICA). ICA is a statistical and computational technique designed to extract hidden factors from random variables expressed as a linear combination of input variables. The concentration (wt. \%) of $\mathrm{TiO}_{2}, \mathrm{Al}_{2} \mathrm{O}_{3}, \mathrm{Fe}_{2} \mathrm{O}_{3}, \mathrm{MgO}, \mathrm{Na}_{2} \mathrm{O}, \mathrm{K}_{2} \mathrm{O}$ were used to extract the chemical weathering variation which is independent from the source rock composition. To evaluate the performance of this newly developed index, we calculated the value of the index for recent soils developed in various climate zones. The new index shows a good correlation with previous index using $\mathrm{CaO}$ (W index) except for the aridisol and vertisol, which developed in Arid climates. For aridisol and vertisol, the value of the new index is constantly higher than $\mathrm{W}$ index. Carbonate minerals derived from meteoric water tend to enrich in aridisol and vertisol thus this result suggests the new index successfully quantifies the weathering intensity of silicate minerals and is robust in the condition of the presence of carbonate minerals. This new index enables the quantitative reconstruction of chemical weathering in the wide range of sedimentary rocks even under the situation of the high presence of non-silicate-bound $\mathrm{CaO}$. 